〈Research Paper〉

\title{
Investigation into the Ecological and Natural Dyeing with Medicinal Plants after Fermentation by NURUK and the Effect of Natural Additives
}

\author{
Youngmi Park \\ Department of Clothing and Fashion, Yeungnam University, Gyeongsan, Korea
}

(Received: November 22, 2012 / Revised: December 10, 2012 / Accepted: December 21, 2012)

\begin{abstract}
The aim of this study was to develop higher-value added dyeing materials with the fermentation-dyeing -mordanting system using only the natural ingredients by integrating traditional fermentation techniques with traditional dyeing technique. Nuruk, which is used mainly to ferment traditional foods, was used as a fermenting agent to ferment 5 different types of materials. Acidic burnt alum and alkaline calcium hydroxide were used as natural mordants. The dyeability checked after fermentation showed that both cotton and silk mordanted with Gardenia jasminoides did not show notable changes, and 10 days of fermentation was found to be appropriate. Sophora japonica L. performed better on cotton materials mordanted with slaked lime, and alkaline mordants were found to be more effective than acidic ones. With Rheum coreanum, a fermentation period of more than 24 days $\left(5^{\text {th }}\right.$ fermentation) worked best on cotton material, showing a 5 fold increase in the K/S value after the $5^{\text {th }}$ slaked lime fermentation than with no fermentation. Rhus javanica L. was found to increase the color fastness to gentle washing and the fastness to light was found to possess 4 means that natural dyed fabric have the highest level of durability, the grade 1 the lowest level of fastness.
\end{abstract}

Keywords: ecological, natural dyeing, medicinal plant, fermentation, NURUK

\section{Introduction}

Natural dyeing refers to the process of coloring using natural colorants from flowers, trees, grass, earth, insects, shells, etc, without any artificial synthesis. On the other hand, 'traditional coloring' refers to the process where natural dyeing is developed vernacularly per region to reflect a range of indigenous geographical and environmental factors. The process follows the traditional method in terms of the mordant, fermentation process, before and after the coloring treatment ${ }^{1)}$.

Natural mordants differ in their mineral contents, and even the same mordant can have different compositions and ingredients according to their origin, time of acquisition and extraction temperature. These complex characteristics provide the depth and naturalness to the color. The mordants remaining after coloring sometimes have health advantages and even treating effects. Generally, elements, such as aluminum, iron, tin, copper and chrome, contribute significantly to the dyeability

${ }^{\dagger}$ Corresponding author: Youngmi Park (ymp9397@yu.ac.kr) Tel.: +82-53-810-2791 Fax.: +82-53-810-4687

(C)2012 KSDF 1229-0033/2012-12/260-269 among synthetic and natural mordants. Brightness, chroma and color differ according to the composition of these elements. The quantity of mordants can alter the physical properties of fabrics. $4 \sim 5 \%$ burnt alum, $1 \sim 2 \%$ iron solution and $3 \sim 5 \%$ acids are generally used. Mordanting also degenerates the color with time, and less than $30 \mathrm{~min}$ is generally recommended. As for the other conditions, a mordanting temperature of $10 \sim 40^{\circ} \mathrm{C}$ is considered appropriate.

Hundreds of papers and patents have been published. The majority of articles focused on improving the colorfastness or photo-stability, on natural dyeing ${ }^{2-9)}$. On the other hand, few studies studied fermentation dyeing or the fermentation of dyes ${ }^{10}$. Of these, very few examined the end-product of the colorant into foods.

The substances used as natural mordant ingredients in this study were an acidic aluminum compound, burnt alum, and an alkaline calcium compound, slaked lime that consist of calcium hydroxide $\left(\mathrm{Ca}(\mathrm{OH})_{2}\right)$. Burnt alum with clear crystals settles the colors in and is used as a waterproofing agent. When fabric is colored with burnt alum dissolved in water, a waterproofing effect is observed as the surface becomes solidified. 
This waterproofing property of is used mainly to color drawing paper, such as Hwaji and red colored paper ${ }^{1)}$. As burnt alum forms a very stable adhesive agent through the coordinate bonding of aluminum ions, it provides little color difference and excellentcolor definition. Moisture and other impurities in burnt alum can be removed by boiling to produce white crystal burnt alum powder, which dissolves in water faster than burnt alum, and results in a brighter color in the coloring process. Meanwhile, slaked lime is a strong alkaline substance that is used mostly to ferment Persicaria tinctoria.

In this study, Nuruk, which is used mainly as a natural fermentation agent in foods, was used to ferment plants, and the dyeability of fabrics dyed with extracted natural colorants was investigated by assessing the color changes and durability.

\section{Experiment}

\subsection{Reagent and specimen}

In this study, the dyeability of fabric with Nuruk fermentation was analyzed according to the natural dye reported in the ancient literature. The dried plant used as dyestuffs were Gardenia jasminoides (Gardenia), Sophora japonica L. (Sophora), Rheum coreanum (Rheum),
Rhus javanica L. (Rhus), Ginkgo biloba L. (Ginkgo) and Isatis tinctoria (Isatis), and all materials were purchased from oriental medicine market in Daegu. Potassium hydroxide $(\mathrm{KOH})$ and an anion surfactant Triton $^{\circledR} \mathrm{X}-100\left(\left(\mathrm{C}_{16} \mathrm{H}_{26} \mathrm{O}_{2}\right) \mathrm{n}\right)$ used for the scouring of cotton, and the mordants used, burnt alum $\left(\mathrm{AlK}\left(\mathrm{SO}_{4}\right)_{2}\right.$ $\left.\cdot 24 \mathrm{H}_{2} \mathrm{O}\right)$ and $\mathrm{Ca}(\mathrm{OH})_{2}$, were purchased from Duksan chemical Co., Ltd. Table 1 lists the specifications of the cotton and silk. The malt and starch syrup were provided by Songhakgokja located in Gwangju, Korea.

\subsection{Scouring}

For each 10x10cm (Fabric weight : 1.20g) cotton sample, $0.2 \mathrm{~g} \mathrm{KOH}$ and $0.2 \mathrm{ml}$ Triton X-100 were dissolved completely in $24 \mathrm{ml}$ of distilled water. The fabric was soaked at a high temperatures $\left(90 \sim 95^{\circ} \mathrm{C}\right)$ and scoured for $1 \mathrm{hr}$. Silk were used as received.

\subsection{Fermentation and extraction of natural colorant}

Nuruk and malt were used mainly for fermenting plants. The composition for fermentation was $500 \mathrm{~g}$ each of Gardenia, Sophora, Rheum, Rhus, Ginkgo and Isatis, $25 \mathrm{~g}$ of Nuruk and $25 \mathrm{~g}$ of malt. All materials were let ferment in covered glass pots with given days. After fermentation, materials for dyeing were extracted liquid state with filtering and continuing to use. Table 2 lists the

Table 1. Specifications of the cotton and silk samples

\begin{tabular}{ccccc}
\hline Fabric & Weave & Density (inch $\left.^{2}\right)$ & Weight $\left(\mathbf{g} / \mathbf{m}^{\mathbf{2}}\right)$ & Thickness $(\mathbf{m m})$ \\
\hline \hline Cotton $100 \%$ & Plain & $73 \times 74$ & 100 & 0.25 \\
Silk & Plain & $160 \times 98$ & 42 & 0.11 \\
\hline
\end{tabular}

Table 2. Fermentation conditions of all plants

\begin{tabular}{ccccc}
\hline Notion & Fermentation (times*) & Date of Extraction & Temperature** & Humidity** $^{* *}$ \\
\hline \hline D10 & 1 & 2012. 09. 20 & $21.0^{\circ} \mathrm{C}$ & $15 \%$ \\
D13 & 2 & 2012.09 .23 & $24.5^{\circ} \mathrm{C}$ & $14 \%$ \\
D17 & 3 & 2012.09 .27 & $24.0^{\circ} \mathrm{C}$ & $14 \%$ \\
D20 & 4 & 2012.09 .30 & $24.0^{\circ} \mathrm{C}$ & $14 \%$ \\
D24 & 5 & 2012.10 .04 & $23.0^{\circ} \mathrm{C}$ & $14 \%$ \\
D31 & 6 & 2012.10 .11 & $25.6^{\circ} \mathrm{C}$ & $14 \%$ \\
D38 & 7 & 2012.10 .18 & $24.0^{\circ} \mathrm{C}$ & $14 \%$ \\
D45 & 8 & 2012.10 .25 & $23.0^{\circ} \mathrm{C}$ & $14 \%$ \\
D52 & 9 & 2012.11 .01 & $23.0^{\circ} \mathrm{C}$ & $14 \%$ \\
D59 & 10 & 2012.11 .08 & $23.0^{\circ} \mathrm{C}$ & $14 \%$ \\
\hline
\end{tabular}

*: extraction interval of the fermented plant, ${ }^{* *}$ : room temperature and humidity 
time elapsed for fermentation, temperature and humidity of the fermented colorant sampled weekly.

\subsection{Dyeing and mordanting}

Batch dyeing most commonly used in traditional dyeing was used regardless of the extracting conditions of the colorant. The dyeing conditions were adjusted and coloring was then performed in a large dyeing plastic bucket. Mordanting was performed after dyeing.

For non-fermentation dyeing, each plant material and water were mixed, heated at $60^{\circ} \mathrm{C}$, dyed for $30 \mathrm{~min}$, washed and then dried in nature. With fermented dyeing, however, plant, water, Nuruk and malt were mixed in a glass bucket.

The resulting mixture was filtered, dyed under same conditions reported above, washed, mordanted, repeated washing thoroughly and then dried. All plants in here were mordant treated with burnt alum at solid state and slaked lime maintaining liquid state. Table 3 lists conditions and methods of dyeing and mordanting.

\subsection{Color depth}

The color depth of the dyed fabric was measured using Color eye-3100 (Gretag Macbeth, US) to determine the brightness of the color $\mathrm{L}^{*}$ and the chromaticity of $a^{*}, b^{*}, h$ and $C$ values.

After measuring the surface reflectance at the maximum absorption wave $(\lambda \max )$, the $\mathrm{K} / \mathrm{S}$ value was calculated using the Kubelka-Munk equation $K / S=(1-R)^{2} / 2 R$, where $\mathrm{R}, \mathrm{K}$ and $\mathrm{S}$ represent the surface reflectance, coefficient of light absorption and the scattering of the dyed fabrics at $\lambda \max$, respectively.

\subsection{Observation of the surface color on dyed fabrics}

The change in the surface color of the fabric after dyeing was externally observed by the naked eye, and photographs were taken to compare the other sample colors.

\subsection{Light and washing fastness}

To measure the durability of the fabric after dyeing, the light fastness was measured with Xenon-arc (ATLAS Ci-4000, Atlas Co. Ltd. US) light using the test method in the KS K ISO 105-B02: 2010 standards. The washing fastness was evaluated by LAUNDER-OMETER (DONG YANG, MODEL: D7-0850) based on the KS K IOS 105-C06 standards. Subsequently, the $\mathrm{L}^{*}, \mathrm{a}^{*}, \mathrm{~b}^{*}$ and $\mathrm{K} / \mathrm{S}$ value were calculated using a color-difference meter (Macbeth color-Eye 3100 ).

\section{Results and Discussion}

\subsection{Properties of the fabrics dyed with Gardenia}

Both of cotton and silk dyed with fermented Gardenia exhibited high dyeability, as shown in Table 4.

Gardenia did not bring a large difference in cotton and silk after mordanting. Only a comparison of ferment for the $5^{\text {th }}$ (24 days) with that of the $1^{\text {st }}$ (10 days), the $\mathrm{R}$ revealed a more than $50 \%$ decrease in cotton. Dyeing with Gardenia showed the good coloring after 10 days, so after fermentation for 10 days, compared to the non-fermentation experiment, highlightingthe need for dyeing.

Table 3. Conditions of dyeing and mordanting on cotton and silk

\begin{tabular}{ccccccc}
\hline \multicolumn{7}{c}{ Dyeing } \\
\hline Fabric & Fabric & Dyestuff* & Water & Temp. & Time & Bath Ratio \\
\hline \hline Cotton & $19 \mathrm{~g}$ & $1.5 \mathrm{~L}$ & $3 \mathrm{~L}$ & $70^{\circ} \mathrm{C}$ & $20 \mathrm{~min}$ & $1: 60$ \\
Silk & $13 \mathrm{~g}$ & $1 \mathrm{~L}$ & $2 \mathrm{~L}$ & $70^{\circ} \mathrm{C}$ & $20 \mathrm{~min}$ & $1: 60$ \\
\hline \multicolumn{7}{c}{ Mordant } \\
\hline Mordant & Mordant & Water & Temp. & Time & pH & Bath Ratio \\
\hline \hline Burnt Alum & $4 \mathrm{~g}$ & $4 \mathrm{~L}$ & $50^{\circ} \mathrm{C}$ & $10 \mathrm{~min}$ & 4.5 & $1: 100$ \\
Slaked Lime & $1 \mathrm{~L}$ & $3 \mathrm{~L}$ & R.T & $10 \mathrm{~min}$ & 11 & $1: 100$ \\
\hline
\end{tabular}

*: fermented dye solution 
Table 4. Color characteristics of Gardenia dyed cotton and silk

\begin{tabular}{|c|c|c|c|c|c|c|c|c|c|}
\hline Mordant Condition & Fabric & Times & $\mathbf{L}^{*}$ & $a^{*}$ & $\mathbf{b}^{*}$ & $\mathbf{C}$ & $\mathbf{h}$ & $\mathbf{R}$ & $\mathbf{K} / \mathbf{S}$ \\
\hline \multirow{2}{*}{ Undyed } & Cotton & - & 83.81 & -0.35 & 0.59 & 0.69 & 120.38 & 61.96 & 0.12 \\
\hline & Silk & - & 81.60 & -0.02 & 3.83 & 3.83 & 90.24 & 49.78 & 0.25 \\
\hline \multirow{4}{*}{ Non-mordant } & \multirow{2}{*}{ Cotton } & 1 & 76.85 & 3.64 & 37.91 & 38.09 & 84.52 & 20.90 & 1.50 \\
\hline & & 5 & 80.12 & -0.01 & 21.73 & 21.73 & 90.02 & 43.06 & 0.58 \\
\hline & \multirow{2}{*}{ Silk } & 1 & 64.27 & -6.07 & 30.67 & 31.27 & 101.20 & 13.81 & 2.69 \\
\hline & & 5 & 68.12 & -3.46 & 20.06 & 20.36 & 99.78 & 24.55 & 1.16 \\
\hline \multirow{4}{*}{ Slaked Lime } & \multirow{2}{*}{ Cotton } & 1 & 77.07 & 2.11 & 36.08 & 36.15 & 86.65 & 22.30 & 1.35 \\
\hline & & 5 & 68.62 & -0.69 & 18.62 & 18.63 & 92.13 & 24.70 & 1.15 \\
\hline & \multirow{2}{*}{ Silk } & 1 & 64.29 & -5.42 & 29.02 & 29.52 & 100.57 & 14.01 & 2.64 \\
\hline & & 5 & 67.58 & -2.62 & 19.73 & 19.90 & 97.55 & 18.89 & 1.74 \\
\hline \multirow{4}{*}{ Burnt Alum } & \multirow{2}{*}{ Cotton } & 1 & 77.76 & 2.91 & 35.94 & 36.05 & 85.37 & 22.91 & 1.30 \\
\hline & & 5 & 80.92 & -0.31 & 19.54 & 19.54 & 90.91 & 38.47 & 0.49 \\
\hline & \multirow{2}{*}{ Silk } & 1 & 65.08 & -6.35 & 29.51 & 30.18 & 102.14 & 14.84 & 2.44 \\
\hline & & 5 & 67.86 & -3.67 & 20.41 & 20.74 & 100.19 & 20.28 & 1.57 \\
\hline
\end{tabular}

\subsection{Properties of the fabrics dyed with Sophora}

As with other fermented colorants, Sophora exhibited higher dyeability for silk. Table 5 shows that the silk with alkaline mordant is more advantageous than that with the acidic one. In particular, for cotton (Table 5), the $\mathrm{R}$ of non-mordanted cotton and silk showed a good coloration compared to the mordanted ones. According to the study, the elapsed time for fermentation did not contribute significantly to the dyeability, even though it decreased with time. This study confirmed that fermentation did not produce a large difference for silk but caused the dyeability to decline for cotton.

\subsection{Properties of the fabrics dyed with Rheum}

For Rheum, better results were generally obtained after more than 24 days fermentation using a slaked lime. As listed in Table 6 , the $\mathrm{K} / \mathrm{S}$ value of cotton increased more than 5 times on the $5^{\text {th }}$ time with slaked lime mordanting compared to that of nonfermentation. Table 6 shows that the K/S value for silk is more than 10 times higher overall, and a naked eye observation confirmed the darker coloration on cotton than silk. In addition Rheum exhibited superior coloration when mordanted with slaked lime after fermented dyeing.

Table 5. Color characteristics of Sophora dyed cotton and silk

\begin{tabular}{|c|c|c|c|c|c|c|c|c|c|}
\hline Mordant Condition & Fabric & Times & $\mathbf{L}^{*}$ & $a^{*}$ & $\mathbf{b}^{*}$ & $\mathbf{C}$ & $\mathbf{h}$ & $\mathbf{R}$ & $\mathbf{K} / \mathbf{S}$ \\
\hline \multirow{2}{*}{ Undyed } & Cotton & - & 83.81 & -0.35 & 0.59 & 0.69 & 120.38 & 61.96 & 0.12 \\
\hline & Silk & - & 81.60 & -0.02 & 3.83 & 3.83 & 90.24 & 49.78 & 0.25 \\
\hline \multirow{4}{*}{ Non-mordant } & \multirow{2}{*}{ Cotton } & 1 & 81.72 & -5.44 & 17.35 & 18.18 & 107.42 & 14.55 & 2.59 \\
\hline & & 5 & 80.21 & -5.44 & 18.39 & 19.17 & 106.47 & 13.55 & 2.76 \\
\hline & \multirow{2}{*}{ Silk } & 1 & 77.33 & -3.63 & 19.70 & 20.03 & 100.43 & 8.11 & 5.21 \\
\hline & & 5 & 75.62 & -3.47 & 23.94 & 24.19 & 98.25 & 5.92 & 7.48 \\
\hline \multirow{4}{*}{ Slaked Lime } & \multirow{2}{*}{ Cotton } & 1 & 77.80 & 0.39 & 11.31 & 11.32 & 88.01 & 34.39 & 0.63 \\
\hline & & 5 & 76.45 & 0.74 & 13.62 & 13.64 & 86.90 & 29.59 & 0.84 \\
\hline & \multirow{2}{*}{ Silk } & 1 & 67.90 & 1.96 & 28.15 & 28.21 & 86.02 & 11.94 & 3.25 \\
\hline & & 5 & 66.29 & 3.54 & 31.34 & 31.54 & 83.56 & 10.11 & 4.00 \\
\hline \multirow{4}{*}{ Burnt Alum } & \multirow{2}{*}{ Cotton } & 1 & 79.47 & -2.96 & 34.67 & 34.79 & 94.89 & 24.50 & 1.22 \\
\hline & & 5 & 77.20 & -2.70 & 44.75 & 44.83 & 93.45 & 44.71 & 2.24 \\
\hline & \multirow{2}{*}{ Silk } & 1 & 76.94 & -4.85 & 42.79 & 43.06 & 96.47 & 14.37 & 2.55 \\
\hline & & 5 & 73.02 & -1.51 & 56.76 & 56.78 & 91.52 & 6.90 & 6.29 \\
\hline
\end{tabular}


Table 6. Color characteristics of Rheum dyed cotton and silk

\begin{tabular}{|c|c|c|c|c|c|c|c|c|c|}
\hline Mordant Condition & Fabric & Times & $\mathbf{L}^{*}$ & $\mathbf{a}^{*}$ & $\mathbf{b}^{*}$ & $\mathbf{C}$ & $\mathbf{h}$ & $\mathbf{R}$ & $\mathbf{K} / \mathbf{S}$ \\
\hline \multirow{2}{*}{ Undyed } & Cotton & - & 83.81 & -0.35 & 0.59 & 0.69 & 120.38 & 61.96 & 0.12 \\
\hline & Silk & - & 81.60 & -0.02 & 3.83 & 3.83 & 90.24 & 49.78 & 0.25 \\
\hline \multirow{4}{*}{ Non-mordant } & \multirow{2}{*}{ Cotton } & 1 & 75.44 & 3.75 & 17.19 & 17.59 & 77.69 & 31.99 & 0.72 \\
\hline & & 5 & 75.21 & 1.78 & 18.09 & 18.18 & 84.38 & 32.11 & 0.72 \\
\hline & \multirow{2}{*}{ Silk } & 1 & 75.21 & 1.78 & 18.09 & 18.18 & 84.38 & 11.90 & 2.56 \\
\hline & & 5 & 44.62 & 15.66 & 22.03 & 27.03 & 54.58 & 6.02 & 3.26 \\
\hline \multirow{4}{*}{ Slaked Lime } & \multirow{2}{*}{ Cotton } & 1 & 70.91 & 5.64 & 12.68 & 13.88 & 66.02 & 28.42 & 0.90 \\
\hline & & 5 & 70.19 & 6.63 & 13.48 & 15.02 & 63.82 & 11.90 & 3.26 \\
\hline & \multirow{2}{*}{ Silk } & 1 & 67.66 & 1.76 & 36.84 & 36.88 & 87.26 & 9.14 & 7.34 \\
\hline & & 5 & 69.67 & 0.80 & 28.38 & 28.39 & 88.38 & 17.76 & 4.52 \\
\hline \multirow{4}{*}{ Burnt Alum } & \multirow{2}{*}{ Cotton } & 1 & 75.92 & 3.04 & 9.34 & 9.82 & 71.99 & 40.01 & 0.45 \\
\hline & & 5 & 75.70 & 2.41 & 11.73 & 11.98 & 78.39 & 37.81 & 0.51 \\
\hline & \multirow{2}{*}{ Silk } & 1 & 70.19 & 6.63 & 13.48 & 15.02 & 63.82 & 14.27 & 1.90 \\
\hline & & 5 & 70.52 & 0.83 & 35.08 & 35.09 & 88.65 & 14.35 & 2.58 \\
\hline
\end{tabular}

\subsection{Properties of the fabrics dyed with Rhus}

Generally, Rhus can dye cotton and silk reasonably well. On the other hand, the K/S value of Rhus for cotton was low indicating a poor dyeability, as listed in Table 7.

Despite the poor fermentation effect, mordanting was more effective when a line equivalent liquid was used on silk. For silk, a shorter fermentation time is considered suitable, as with Gardenia.

\subsection{Properties of the fabrics dyed with Ginkgo}

The Ginkgo used in this study was collected in fall season, and were near green in color.
The chlorophyll content is high at that time but the natural color turns brown when heated to $70^{\circ} \mathrm{C}$.

Therefore, almost no coloration is visible regardless of mordanting and fermentation and the components in Ginkgo are believed to be influential.

In other words, Chlorophyll, the pigment in Ginkgo, is denatured by heating and turns brown, losing its original property. Moreover, it can no longer react with the functional groups of the fabric.

Therefore, the dyeability of both cotton and silk in Table 8 were almost unchanged after the fermentation and mordant treatments.

Table 7. Color characteristics of Rhus dyed cotton

\begin{tabular}{|c|c|c|c|c|c|c|c|c|c|}
\hline Mordant Condition & Fabric & Times & $\mathbf{L}^{*}$ & $\mathbf{a}^{*}$ & $\mathbf{b}^{*}$ & $\mathbf{C}$ & $\mathbf{h}$ & $\mathbf{R}$ & $\mathbf{K} / \mathbf{S}$ \\
\hline \multirow{2}{*}{ Undyed } & Cotton & - & 83.81 & -0.35 & 0.59 & 0.69 & 120.38 & 61.96 & 0.12 \\
\hline & Silk & - & 81.60 & -0.02 & 3.83 & 3.83 & 90.24 & 49.78 & 0.25 \\
\hline \multirow{4}{*}{ Non-mordant } & \multirow{2}{*}{ Cotton } & 1 & 83.12 & -0.79 & 3.86 & 3.95 & 101.60 & 50.58 & 0.24 \\
\hline & & 5 & 82.31 & -1.00 & 4.73 & 4.84 & 101.94 & 46.68 & 0.31 \\
\hline & \multirow{2}{*}{ Silk } & 1 & 77.84 & 0.00 & 9.15 & 9.15 & 90.03 & 34.44 & 0.63 \\
\hline & & 5 & 77.40 & -0.02 & 11.07 & 11.07 & 90.09 & 30.97 & 0.77 \\
\hline \multirow{4}{*}{ Slaked Lime } & \multirow{2}{*}{ Cotton } & 1 & 74.86 & 0.47 & 18.96 & 18.96 & 88.57 & 34.44 & 0.62 \\
\hline & & 5 & 77.69 & -0.24 & 12.95 & 12.95 & 91.05 & 33.31 & 0.67 \\
\hline & \multirow{2}{*}{ Silk } & 1 & 53.25 & 3.00 & 25.43 & 25.61 & 83.28 & 5.85 & 7.58 \\
\hline & & 5 & 69.15 & 1.24 & 21.87 & 21.91 & 86.75 & 9.51 & 2.27 \\
\hline \multirow{4}{*}{ Burnt Alum } & \multirow{2}{*}{ Cotton } & 1 & 80.89 & -0.46 & 4.26 & 4.28 & 96.16 & 23.37 & 1.27 \\
\hline & & 5 & 82.17 & -0.78 & 5.69 & 5.74 & 97.81 & 47.99 & 0.29 \\
\hline & \multirow{2}{*}{ Silk } & 1 & 76.89 & 0.22 & 8.80 & 8.80 & 88.54 & 33.77 & 0.65 \\
\hline & & 5 & 77.29 & 0.09 & 11.58 & 11.58 & 89.56 & 30.84 & 0.77 \\
\hline
\end{tabular}


Table 8. Color characteristics of Ginkgo dyed cotton and silk

\begin{tabular}{|c|c|c|c|c|c|c|c|c|c|}
\hline Mordant Condition & Fabric & Times & $\mathbf{L}^{*}$ & $\mathbf{a}^{*}$ & $\mathbf{b}^{*}$ & $\mathbf{C}$ & $\mathbf{h}$ & $\mathbf{R}$ & $\mathbf{K} / \mathbf{S}$ \\
\hline \multirow{2}{*}{ Undyed } & Cotton & - & 83.81 & -0.35 & 0.59 & 0.69 & 120.38 & 61.96 & 0.12 \\
\hline & Silk & - & 81.60 & -0.02 & 3.83 & 3.83 & 90.24 & 49.78 & 0.25 \\
\hline \multirow{4}{*}{ Non-mordant } & \multirow{2}{*}{ Cotton } & 1 & 82.44 & -1.12 & 3.69 & 3.85 & 106.89 & 46.07 & 0.32 \\
\hline & & 5 & 83.30 & -0.39 & 1.65 & 1.70 & 103.36 & 58.49 & 0.15 \\
\hline & \multirow{2}{*}{ Silk } & 1 & 80.09 & -0.45 & 6.04 & 6.06 & 94.24 & 37.93 & 0.51 \\
\hline & & 5 & 79.39 & 0.17 & 6.68 & 6.68 & 88.50 & 41.48 & 0.41 \\
\hline \multirow{4}{*}{ Slaked Lime } & \multirow{2}{*}{ Cotton } & 1 & 83.30 & -0.83 & 3.46 & 3.56 & 103.45 & 53.32 & 0.20 \\
\hline & & 5 & 83.32 & -0.34 & 1.59 & 1.63 & 102.12 & 58.68 & 0.15 \\
\hline & \multirow{2}{*}{ Silk } & 1 & 79.19 & -0.10 & 9.52 & 9.52 & 90.60 & 36.47 & 0.55 \\
\hline & & 5 & 79.04 & 0.70 & 8.04 & 8.07 & 85.05 & 39.20 & 0.47 \\
\hline \multirow{4}{*}{ Burnt Alum } & \multirow{2}{*}{ Cotton } & 1 & 83.43 & -2.35 & 7.14 & 7.51 & 108.25 & 49.96 & 0.25 \\
\hline & & 5 & 82.51 & -0.20 & 1.90 & 1.91 & 96.01 & 56.57 & 0.17 \\
\hline & \multirow{2}{*}{ Silk } & 1 & 79.58 & -1.58 & 9.76 & 9.89 & 99.18 & 36.05 & 0.57 \\
\hline & & 5 & 79.81 & 0.19 & 7.30 & 7.30 & 88.54 & 41.27 & 0.42 \\
\hline
\end{tabular}

\subsection{Properties of the fabrics dyed with Isatis}

Isatis is one of the most commonly used fermenting plant dyes. Powder state Isatis was fermented 10, 24 and 59 days. As listed in Table 9, the K/S value for both cotton and silk was relatively constant after dyeing without mordants, which shows that the Isatis fermentation method used in this study was inappropriate. Fermented-Isatis actually requires alkali to make it water-soluble. In this study, however, the $\mathrm{pH}$ turned toward the acidic, which it actually a common phenomenon because the food or plant changes to an acidic state through acidic fermentation due to the increase in hydrogen ion concentration by fermentation. As Isatis is not water-soluble, the addition of different fermentation agents than water-soluble ones is required. Fermenting using alkali, such as lixivium which the alkaline solution obtained by wood as with water, to make it water-soluble can be another option.

\subsection{Washing fastness of natural dyed cotton and silk by $\mathrm{K} / \mathrm{S}$}

The washing fastness was evaluated using a washing tester after eliminating the fabric a number of times to remove any left over dye. Table 10 lists the results of the washing fastness of different dye- and mordanttreated cotton and silk.

For Gardenia, the K/S value after washing showed a decrease for both cotton and silk. A decrease in fastness was observed with the fabric, which was dyed once past 10 days of fermentation, exhibiting good dyeability. Relatively easy coloring might have resulted in easy discoloring. The silk dyed once, which had excellent coloration, experienced a large decrease in fastness, whereas the decline was rather gradual for cotton.

For Sophora, the dyeability after washing showed an overall decline.

Table 9. Color characteristics of Isatis-dyed cotton and silk

\begin{tabular}{|c|c|c|c|c|c|c|c|c|c|}
\hline Mordant Condition & Fabric & Times & $\mathbf{L}^{*}$ & $\mathbf{a}^{*}$ & $\mathbf{b}^{*}$ & $\mathbf{C}$ & $\mathbf{h}$ & $\mathbf{R}$ & $\mathbf{K} / \mathbf{S}$ \\
\hline \multirow{2}{*}{ Undyed } & Cotton & - & 83.81 & -0.35 & 0.59 & 0.69 & 120.38 & 61.96 & 0.12 \\
\hline & Silk & - & 81.60 & -0.02 & 3.83 & 3.83 & 90.24 & 49.78 & 0.25 \\
\hline \multirow{6}{*}{ Non-mordant } & \multirow{3}{*}{ Cotton } & 1 & 77.32 & -3.07 & 0.69 & 3.15 & 167.36 & 43.97 & 0.36 \\
\hline & & 5 & 76.38 & -2.39 & -0.06 & 2.39 & 181.45 & 39.45 & 0.47 \\
\hline & & 10 & 80.48 & -1.93 & 2.22 & 2.94 & 131.06 & 29.91 & 0.82 \\
\hline & \multirow{3}{*}{ Silk } & 1 & 75.31 & -2.46 & 3.77 & 4.50 & 123.09 & 37.28 & 0.53 \\
\hline & & 5 & 75.64 & -1.22 & 6.11 & 6.23 & 101.31 & 0.51 & 0.51 \\
\hline & & 10 & 78.43 & -0.40 & 5.97 & 5.98 & 93.83 & 29.93 & 0.82 \\
\hline
\end{tabular}


Table 10. Fastness to washing of cotton depends on the dye and mordant conditions as indicated by the K/S value

\begin{tabular}{|c|c|c|c|c|c|c|c|c|}
\hline \multirow{2}{*}{ Fabric } & \multirow{2}{*}{ Condition } & \multirow{2}{*}{ Time } & \multirow{2}{*}{ Wash } & \multicolumn{5}{|c|}{ Fermented Natural Dye } \\
\hline & & & & Gardenia & Sophora & Rheum & Rhus & Ginkgo \\
\hline \multirow{13}{*}{ Cotton } & Undyed & - & - & & & 0.12 & & \\
\hline & \multirow{4}{*}{ Non-mordant } & \multirow{2}{*}{1} & Before & 1.50 & 2.51 & 0.72 & 0.24 & 0.32 \\
\hline & & & After & 0.75 & 2.78 & 1.18 & 0.69 & 0.52 \\
\hline & & \multirow{2}{*}{5} & Before & 0.59 & 2.76 & 0.72 & 0.31 & 0.15 \\
\hline & & & After & 0.47 & 0.55 & 0.89 & 0.59 & 0.30 \\
\hline & \multirow{4}{*}{ Slaked Lime } & \multirow{2}{*}{1} & Before & 1.35 & 0.63 & 0.90 & 0.62 & 0.20 \\
\hline & & & After & 0.71 & 1.45 & 1.25 & 0.77 & 0.50 \\
\hline & & \multirow{2}{*}{5} & Before & 1.15 & 0.84 & 0.93 & 0.67 & 0.15 \\
\hline & & & After & 0.46 & 0.56 & 0.96 & 0.67 & 0.29 \\
\hline & \multirow{4}{*}{ Burnt Alum } & \multirow{2}{*}{1} & Before & 1.30 & 1.22 & 0.45 & 1.26 & 0.25 \\
\hline & & & After & 0.76 & 0.57 & 1.20 & 0.84 & 0.42 \\
\hline & & \multirow{2}{*}{5} & Before & 0.49 & 2.24 & 0.51 & 0.28 & 0.17 \\
\hline & & & After & 0.45 & 0.48 & 0.89 & 0.61 & 0.27 \\
\hline \multirow{13}{*}{ Silk } & Undyed & - & - & & & 0.25 & & \\
\hline & \multirow{4}{*}{ Non-mordant } & \multirow{2}{*}{1} & Before & 2.69 & 5.21 & 2.56 & 0.62 & 0.51 \\
\hline & & & After & 2.03 & 1.45 & 4.75 & 3.93 & 0.53 \\
\hline & & \multirow{2}{*}{5} & Before & 1.16 & 7.48 & 3.26 & 0.76 & 0.41 \\
\hline & & & After & 1.59 & 2.00 & 4.92 & 1.43 & 0.49 \\
\hline & \multirow{4}{*}{ Slaked Lime } & \multirow{2}{*}{1} & Before & 2.64 & 3.25 & 7.34 & 7.58 & 0.55 \\
\hline & & & After & 2.06 & 2.61 & 7.56 & 6.88 & 0.53 \\
\hline & & \multirow{2}{*}{5} & Before & 1.74 & 4.00 & 4.52 & 2.27 & 0.47 \\
\hline & & & After & 1.55 & 3.11 & 7.50 & 2.10 & 0.48 \\
\hline & \multirow{4}{*}{ Burnt Alum } & \multirow{2}{*}{1} & Before & 2.44 & 2.55 & 1.90 & 0.65 & 0.57 \\
\hline & & & After & 1.95 & 1.38 & 3.55 & 5.67 & 0.48 \\
\hline & & \multirow{2}{*}{5} & Before & 1.57 & 6.28 & 2.58 & 0.77 & 0.42 \\
\hline & & & After & 1.59 & 2.10 & 4.50 & 0.92 & 0.47 \\
\hline
\end{tabular}

In the case of silk, which has good dyeability, the fastness decreased after washing. In contrast, the fastness of cotton decreased gently showing half that of silk.

For Rheum, the dyeability for both cotton and silk remained fine, and silk exhibited a superior $\mathrm{K} / \mathrm{S}$ value. The durability after washing revealed an increase for both cotton and silk.

The fastness of Rhus increased for cotton, which was similar to the case of Rheum. Unlike mordant with slaked lime, burnt alum mordanted cotton and silk showed an increase in washing fastness due to the effect of aluminum ions, which shows that the effect of dissolved metal ions was not excluded.

The fastness result of Ginkgo was increased slightly. When the $\mathrm{K} / \mathrm{S}$ value is less than 1 , it is impracticable to decide that the dyeability is changed through washing.
The washing fastness of Isatis according to the K/S value was also very poor. The $\mathrm{K} / \mathrm{S}$ increased in some cases but are arrangement of the remaining dye after coloring was considered the cause, as explained previously. Interpreting a low $\mathrm{K} / \mathrm{S}$ value as an increase in was hability is impractical and not recommended.

\subsection{Measuring the light fastness and appearance color of dyed cotton and silk}

Table 11 shows the light fastness and the surface properties according to a change in surface color. In results of light fastness, most of the dyed fabrics with non-fermented plants revealed grade 1-3 (not seen data). A naked eye observation of the change in surface color of the fabric after dyeing confirmed the differences according to the number of dyeing steps and the elapsed time of fermentation. 
Table 11. Light fastness and surface color of cotton and silk depends on fermented plant materials

\begin{tabular}{|c|c|c|c|c|c|c|}
\hline Materials & Times* & Sample & Mordant & Grade & Color & Stain \\
\hline Gardenia & 1 & Cotton & Non-mordant & $1-2$ & & No \\
\hline \multirow{6}{*}{ Sophora } & 1 & Cotton & Burnt Alum & $3-4$ & & No \\
\hline & \multirow{2}{*}{1} & \multirow{2}{*}{ Silk } & Non-mordant & 4 & & No \\
\hline & & & Burnt Alum & $1-2$ & & No \\
\hline & 5 & Cotton & Burnt Alum & $1-2$ & & A little \\
\hline & \multirow{2}{*}{5} & \multirow{2}{*}{ Silk } & Non-mordant & 2 & & No \\
\hline & & & Burnt Alum & $1-2$ & & No \\
\hline \multirow{2}{*}{ Rheum } & 1 & \multirow{2}{*}{ Silk } & Non-mordant & 3 & & No \\
\hline & 5 & & Non-mordant & $1-2$ & & No \\
\hline \multirow{2}{*}{ Rhus } & \multirow{2}{*}{5} & \multirow{2}{*}{ Silk } & Non-mordant & $3-4$ & $=$ & No \\
\hline & & & Slaked Lime & 3 & & No \\
\hline
\end{tabular}

Times*: 1 and 5 means 10 and 24 days after fermentation at $21^{\circ} \mathrm{C}$ and $23^{\circ} \mathrm{C}$, respectively

This difference is believed to have been caused by the physiochemical properties of natural dyeing that increased the number of contact processes that repeatedly affected the fabric surface. For cotton, the fastness can increase to 3-4 grade according to the mordants. For silk, however, despite the good coloration by a naked eye observation, the light fastness decreased to 1-2. This was not caused by the fermentation period or difference in fermentation process of the dye, but to the problem between the chemical bonding site and functional group of the specimen. The temperature and $\mathrm{pH}$ in the fermentation process of the dye are believed to be the largest factor, and calls for further studies on varying the fermentation temperature and $\mathrm{pH}$. In terms at the individual result for the light fastness per colorant, Gardenia requires further study in terms of pre-mordanting, and variations of the dyeing conditions, such as the character of dye, dyeing temperature and time etc. For dyeability, Sophora exhibited a slightly better result with non-fermentation than fermentation, and the alkaline mordant was more effective for mordanting. In particular, a superior fastness to light of 3-4 was observed with non- mordanting and burnt alum mordanting than with the other dyes.

Like the dyeability, silk with non-mordanting exhibited a satisfactory light fastness of 4 .
When cotton was mordanted with burnt alum after 15 days fermentation, the light fastness decreased from 3-4 to $1-2$, and that of silk with non-mordanting also decreased from grade 4 to 3 . Although the difference between pre and post fermentation was not great, it generally showed a decline. The light fastness of Sophora was better without a mordant than with a mordant. Therefore, additional experiments on varying the fermentation conditions will be needed in the future. The dyeability of Rheum showed the best performance when treated with lime mordanting. The durability of cotton did not decrease, even after a prolonged fermentation time, but silk showed weaker fastness when it was left to ferment longer. Although the $\mathrm{K} / \mathrm{S}$ value after dyeing with Rhus was quite low, it showed a higher than 3 grade for non- and lime mordanting. Rhus exhibited better coloration after the $5^{\text {th }}$ fermentation than that after the $1^{\text {st }}$. The coloration of cotton could not be identified by the naked eye. Hence, only fastness of silk was analyzed, which exhibited superior durability than grade 3 . The dyeability of Isatis showed a very low $\mathrm{K} / \mathrm{S}$ value at approximately 0.8 after 59 days, and almost no coloration was observed by the naked eye. Finally, Ginko leaves were picked when they were still green, fermented and colored.

The analysis revealed slightly better dyeability for 
silk than cotton but the light fastness after 10 and 24 days was similar to the color in the picture, and settled in for a low 1-2. Despite there being almost no coloration visible to the observation compared to the other colorants, it was rated at 1-2. As described in the above mentioned analysis result of the fastness under a range of conditions, the use of mordant could improve the coloration, but fundamental fading by light could decrease the light fastness due to metal ion contained in the mordants, whereas a perfect chelate bond would sustain the dyed color as it is and retain durability. Therefore, the reaction mechanism of the dyes by fermentation requires further study.

\subsection{Dyeing stain}

In this study, cotton and silk were treated with natural mordants, and the coloration of the fabric immediately after dyeing was evaluated using the $\mathrm{K} / \mathrm{S}$ value through the CCM. A decrease in coloration compared to chemically pre-treated cotton was expected, and the difference in coloration was observed according to the type of mordant and the amount. No accurate measurement method exists to estimate the dyeing stain, and researchers have generally made naked eye judgments. Table 11 presents external observation of the dyeing stain on common cotton and silk. This is considered to be caused when the dye spreads rapidly to the surface of the fabric due to hygroscopic property of the fabric, adhesive property of the dye component to the fabric and the hydrophilicity of the dye. A number of experiments have been conducted to prevent this from occurring. The dyeing stains could be reduced using $\mathrm{Na}_{2} \mathrm{CO}_{3}$, which was used as a dyeing supplement, causing less dye staining on silk than cotton but a change in $\mathrm{pH}$ was observed. The grade of the occurrence of dyeing stains were used to judge the specimen used in the analysis of light fastness, which exhibited superior coloration to the naked eye. As a result, silk showed no dyeing stains by any of the fermented colorants. In particular, Gardenia showed no signs of dyeing stains, even on cotton fabric dyed once. On the other hand, a few dyeing stains remained for cotton fabrics dyed with Sophora and Rheum.

\section{Conclusions}

This study examined the light fastness and the color of fabrics dyed naturally with medicinal plants that are beneficial to the human body as a colorant. And the study also assessed the change in dyeability according to the $\mathrm{pH}$ using natural alkaline burnt alum and acidic slaked lime. To investigate the dyeability and durability, a number of plant colorants were first fermented with Nuruk, which is commonly used for fermenting in Korean traditional foods. The results are as follows. The use of a mordant can improve the dyeability, but fundamental fading by light could reduce the light fastness. Fermented Gardenia had a similar effect on cotton and silk, and 10 days-fermentation was considered to be the proper time for good coloration. Sophor worked better on cotton when used with slaked lime water, and alkaline mordants were more advantageous than acidic ones. Rheum fermented over 24 days exhibited excellent $\mathrm{K} / \mathrm{S}$ value on cotton compared to lime treated with no fermentation. For Rhus, the dyeability of silk was improved with no long or short elapsed times for fermentation, and the mordanted fabric showed a slight increase in washing fastness. Regarding the most important property, it was confirmed that the light fastness of Rhus had a high durability of approximately grade 4 .

\section{Acknowledgement}

This study was supported by Basic Science Research Program through the National Research Foundation of Korea (NRF) funded by the Ministry of Education, Science and Technology (Grant No. 212-C-000-194).

\section{References}

1. J. H. Yu and Y. R. Beun, "Bio Technology", Hyoilbooks, Seoul, 2008.

2. S. N. Ali, Reusing Wastewater of Madder Natural Dye for Wool Dyeing, J. of Cleaner Production, 19 (6-7), 775(2011).

3. K. W. Lee, J. H. Lee, S. J. Eum, E. M. Bae, T. Y. Kim and S. H. Yoon, Natural Dyeing of Sangju Silk with Mulberry Extract Solution, Textile 
Coloration and Finishing(J. Korean Soc. Dye. and Finish.), 22(3), 207(2010).

4. E. S. Im, H. S. Lee and C. H. Han, Dyeability and Functionality of Silk Fabrics Dyed with Jeju Scoria, Textile Coloration and Finishing(J. Korean Soc. Dye. and Finish.), 23(3), 187(2011).

5. Y. M. Park, K. Koo, S. S. Kim and J. D. Choe, Improving the Colorfastness of Poly(ethylene terephthalate) Fabrics with the Natural Dye of Caesalpinia sappan L. Wood Extract and the Effect of Chitosan and Low-temperature Plasma, J. Appl. Polym. Sci., 109(1), 160(2008).

6. B. H. Park, I. J. Lee, M. H. Jang and J. U. Lee, US Pat. 2010-278888(2010).

7. F. A. Nagia and R. S. R. EL-Mohamedy, Dyeing of Wool with Natural Anthraquinone Dyes from
Fusarium Oxysporum, Dyes and Pigments, 75(3), 550(2007).

8. S. Padma, R. S. Vankar and V. Avani, Enzymatic Natural Dyeing of Cotton and Silk Fabrics without Metal Mordants, J. of Cleaner Production, 15(15), 1441(2007).

9. P. Velmurugan, S. Kamala-Kannan, V. Balachandar, P. Lakshmanaperumalsamy, J. C. Chae and B. T. Oh, Natural Pigment Extraction from Five Filamentous Fungi for Industrial Applications and Dyeing of Leather, Carbohydrate Polymers, 79(2), 262(2010).

10. P. Nigam, G. Armour, I. M. Banat, D. Singh and R. Marchant, Physical Removal of Textile Dyes from Effluents and Solid-state Fermentation of Dyeadsorbed Agricultural Residues, Bioresource Technology, 72(3), 219(2000). 